\title{
Sexual Abuse Histories Among Incarcerated Older Adult Offenders: A Descriptive Study
}

\author{
Mary Beth Morrissey, Deborah Courtney and Tina Maschi \\ Fordham University, Graduate School of Social Service
}

USA

\section{Introduction}

In the United States today, there are over 2.2 million incarcerated adults held in custody in U.S. state or federal prisons or local jails (Glaze, 2010). Prison facilities are oftentimes filled to capacity or in some cases, so overcrowded that conditions violate the constitutional rights of adults in prison (Brown v. Plata, 2011; Sabol \& West, 2009; West \& Sabol, 2008). Official statistics paint a contemporary portrait of the 1.5 million adult sentenced prisoners under state or federal jurisdiction who are mostly male $(93 \%)$ and from diverse racial and ethnic backgrounds including Black American (36\%), Caucasian (31\%), and Latino (20\%)(West \& Sabol, 2008). Black males continue to have the highest incarceration rates across all age categories compared to White or Latino males (Sabol \& Couture, 2008). There is a growing number of older adults in both state and federal prisons, approaching nearly $5 \%$ of inmates 55 and older in custody of state prisons in 2007, and over 7\% of inmates 56 and older in federal prison in 2009 (Cox \& Lawrence, 2010; Sabol \& Couture, 2008). This aging prisoner population, which is five times larger than in 1990, presents a significant public health challenge that the correctional system is not adequately equipped to address (Falter, 1999; Reimer, 2008). Moreover, the high prevalence of trauma among older adults in prison and psychological distress associated with trauma experiences raise serious concerns about the well-being of this population (Krause, 2004). Studies have shown that approximately $93 \%$ of juvenile and adult prisoners have had prior exposure to trauma, such as being a victim of and/or witness to sexual abuse (Harlow, 1999).

The high prevalence of trauma histories, especially earlier life sexual victimization, within the incarcerated older adult offenders is a major concern. If these traumatic histories go unidentified and untreated, it is likely that unresolved subjective distress about these past events may be heightened, resulting in persistent or resurfacing of post-traumatic stress symptoms or increased likelihood of criminal offending including the perpetration of sexual abuse (Leach, Burgess, Holmwood, 2008). Identifying the types of traumatic experiences, particularly sexual abuse histories, experienced by older adult offenders is important to developing comprehensive approaches to assessment, treatment and program planning for older adults in prison (Dawes, 2009; Rikard \& Rosenberg, 2007; Shimkus, 2004). While there are various types of traumatic and stressful experiences in the lives of incarcerated older adults, sexual victimization is an area that demands individualized attention, especially given the high rates of sexual victimization histories prior to prison that occur within this population. For instance, traumatic sexual victimization experiences among offenders occur 
at much higher rates than in the general population (Teplin, 1990). Individuals who experienced traumatic experiences prior to prison have a greater likelihood of experiencing revictimization while in prison (Struckman-Johnson, Struckman-Johnson, Rucker, Bumby, and Donaldson, 1996). Failure to recognize and design appropriate responses and interventions to address sexual abuse and the cycle of "retraumatization" and its concomitant risks of sexual abuse perpetration, may result in ongoing uninterrupted trends of trauma experiences among older adults in prison who themselves are victims in urgent need of specialized care (Maschi, Gibson, Zgoba, \& Morgen, 2011).

\section{Trauma, sexual abuse, and life course consequences}

Research indicates that childhood or adult trauma, such as being a victim or witness to sexual abuse, may have a persistent or intermittent mental or physical effect, such as continued revictimization, psychiatric disorders, maladaptive stress responses, physical disabilities, and even early death (Acierno, Hernandez, Amstadter, Resnick, Steve, Muzzy, \& Kilpatrick, 2010; Gagnon \& Hersen, 2000; Maschi, 2006). The type and timing of symptoms may vary. For example, subjective traumatic experiences that first occur in childhood may be accompanied by feelings of intense fear, helplessness, or horror (APA, 2000; Hiskey, Luckey, Davies, \& Brewin, 2008). These feelings may occur immediately following the childhood traumatic event or remain dormant and then resurface in later life (Hiskey, Luckey, Davies, \& Brewin, 2008). Evidence also suggests that when a traumatic experience is marked by intensity, duration, and chronicity, such as a prolonged exposure to sexual abuse, the likelihood of post-traumatic stress symptoms is prolonged, and may extend into later years in life (Neal et al., 1995). Research on the temporal effects of childhood trauma, especially on later life functioning, has been minimally explored. While the data are scant, findings indicate that childhood trauma exposure may result in minor psychological distress or lead to more severe mental health consequences, such as posttraumatic stress disorder (PTSD), depression, anxiety, and cognitive impairment (Maschi et al., 2011, Neal et al., 1995; Shmotkin \& Litwin, 2009). It is important to note that age plays a significant role in this relationship, as older adults with earlier life trauma have been shown to have a higher risk of revictimization for elder abuse, especially if their social support network is limited (Acierno et al., 2007). Evidence suggests that older adults in prison are at an even increased risk of sexual victimization by other prisoners or staff (Dawes, 2009).

These types of childhood experiences have been found to have pronounced and long-lasting effects, especially among criminal justice populations (Abram et al., 2007; Ford et al., 2004; James \& Glaze, 2006). Several mental health theoreticians have explanations for the impact of psychosocial stressors (such as being a victim and/or witness to violence, or losing a loved one) on mental health and aggressive and self-destructive behaviors (van der Kolk, McFarlane, \& Weisaeth, 1996). Bessel van der Kolk (1987) offers a biopsychosocial explanation for the impact of psychosocial stressors on mental health. He sees mental health disorders as more complex than the diagnostic label given to the client. In other words, mental health disorders are not interpreted as solely biologically or genetically driven, but in fact are understood as multidimensional in nature and influenced by one's ability to cope with adverse life experiences. Van der Kolk (1987) asserts that when children experience trauma they can be deeply affected and develop jaded expectations about the world and the safety and security of their lives, and such experiences and responses may compromise their psychological, emotional, social and behavioral functioning (van der Kolk \& Fisler, 1994). More specifically, van der Kolk et al. (1996) explained that traumatic experiences can consequently impact individuals' ability to regulate affect and control impulse, manifesting in symptoms of mental 
health disorders. It is imperative to consider such theoretical understandings of trauma in the discussion of incarcerated offenders as difficulty regulating affect and inability to control impulse can lead to many illegal behaviors and consequently a prison sentence.

\section{Sexual abuse among older adults in prison and the community}

More recent studies have begun to expose the life course experience of older adults in the criminal justice system (Maschi, Dennis, Gibson, MacMillan, Sternberg, Hom, 2011). For example, in a review of case records, Haugebrook, Zgoba, Maschi, Morgen, \& Brown (2010) found upwards of $80 \%$ of older males in prison had documented histories of one or more traumatic or stressful life events that occurred during childhood and/or adulthood. About $20 \%$ had childhood sexual or physical assault histories. These traumatic experiences ranged from a single event to multiple traumatic and related stressful life events. Being a victim of childhood physical or sexual abuse is an example of a singular traumatic event of significant magnitude that has been linked to later life adverse mental and physical health among older adults (Lamet, Szuchman, Perkel, \& Walsh, 2009; Shmotkin \& Barilan, 2002). Other studies with incarcerated women find an even higher rate of sexual abuse histories (McDanielWilson \& Belknap, 2008). For example, McDaniels-Wilson and Belknap (2008) found that $70 \%$ of their sample of 391 incarcerated women had been raped at least once, while half of them endorsed a history of childhood sexual abuse. Not only do many prisoners come into the system with a history of sexual abuse, but there are also frequent reports of sexual violence occurring within the prison systems (Maschi et al., 2011).

For trauma victims in prison, the prison environment itself is an additional source of trauma and stress, especially among older offenders (Goff. Rose, Rose, \& Purves, 2007; Stojkovic, 2007). Struckman-Johnson and colleagues (1996) report that in a sample of 1,800 adult offenders (in which $8 \%$ of the sample was aged 48 and older), 1 out of 5 were found to have been pressured or forced to have at least one unwanted sexual contact, including anal, vaginal, or oral intercourse, or being a victim of gang rape. The agency, Stop Prisoner Rape, also reports that there were frequent rapes and other forms of sexual abuse being perpetrated by correction officers within the prisons (Stop Prisoner Rape Report, 2003). In addition, offenders with histories of sexual abuse compounded with other traumas are more vulnerable while in prison. For example, Hochstetler, Murphy, and Simons (2004) found that prior victimization experiences predicted revictimization in prison.

It is imperative to consider the additional risk that older age places on incarcerated offenders with regard to past and present sexual victimization. For instance, incarcerated older adults are considered at the highest risk for victimization because of their decreasing ability to defend themselves against younger prisoners or staff (Dawes, 2009). Along the same lines older adults in frail health are at higher risk of all forms of elder abuse, which could include sexual assaults, in prison (Goff et al., 2007; Stojkovic, 2007). Furthermore, older adult offenders also have additional age specific stressors, such as concerns over failing health and the fear of dying in prison (Aday, 2006; Marushak, 2008), in addition to the physical vulnerabilities presented by the aging process. This cumulative effect of trauma and stress can have a significant adverse effect on their physical and mental well-being (Maschi et al., 2011).

These age related health and mental health factors are extremely important to consider for a number of reasons. First, Draper and colleagues (2008) found that older adults in the community with childhood physical and sexual abuse histories were at the highest risk of later poor physical health and mental health compared to those who did not have these 
experiences. Second, Yehuda and colleagues (1995) found a positive association between childhood trauma combined with current experiences of age-related stress and the severity of post-traumatic stress symptoms among older adults in the community. Third, Hiskey and colleagues (2008) report that older adults older adults in the community, who were childhood trauma survivors, experienced later life reactivation of traumatic memories, which had intense and vivid aspects with the same subjective potency as the original traumatic event. In sum, the age-related stressors that incarcerated adults are coping with while in prison, such as increased risk of sexual victimization, can likely trigger earlier traumatic memories and experiences leading to significant impairment and potential post-traumatic stress symptoms.

\section{Purpose of book chapter}

Research on trauma in the criminal justice population has commonly examined sexual victimization (e.g., Harlow, 1999; Maschi et al., 2011). These prior studies primarily document whether or not a sexual victimization has occurred or not. We lack information about the various types of sexual victimization (from minor to severe types), and the age or developmental period at which it occurred. There has been little exploration of older adults' life-course subjective experiences at the time of occurrence of sexual victimization and currently while living through later life in prison. There also is a dearth of knowledge on how these different types of sexual victimization are related to sexual offending among older adults in prison.

Therefore, the purpose of this descriptive study is to examine patterns of sexual abuse over the life-course, and temporal subjective experiences, both past and present, of sexual abuse among a sample of incarcerated older adults. It also provides a preliminary analysis of the data that examines the relationship between the different subtypes of trauma and sexual offendings. Research in this area can help expose the unexplored dimensions of sexual abuse in this largely neglected population. These findings have significance for improving trauma-informed responses among older adults, especially while in prison. As a result of examining this data, the need for effective trauma assessment in the correctional system, including specific sexual victimization assessment, along with efficacious trauma treatment modalities, is underscored. The urgency and magnitude of this public health problem is highlighted and the promise of treatment that can be used to interrupt the cycle of revictimization among these vulnerable older adults in prison.

\section{Study methods}

This cross-sectional correlational design used a stratified random sample of older (age 50 and above) offenders drawn from a state correctional department's administrative databases. There were 667 participants that completed a self report mail survey that used a modified version of the Life Stressors Checklist-Revised (LSC-R).

\subsection{Research design}

This study was conducted in September 2010 in 13 prison facilities across a statewide department of correction (DOC) located in the northeast United States. Of approximately 25,000 prisoners housed in this correctional system in January 2010, approximately $6 \%$ $(n=1,500)$ were aged 50 and older. Information to create the sampling frame included the DOC administrative records data for State Bureau of Identification (SBI) number and age. 
The DOC generated the sampling frame for the study with a list of names, so that invitations and anonymous surveys could be mailed to potential participants and return correspondence could be received.

The final sample size consisted of 667 English-speaking prisoners (aged 50 and older) who responded to the survey, which resulted in a response rate of $43 \%$. This estimate falls within the higher range of expected mail response rates, which are $20-40 \%$ for prison populations (Hochstetler et al., 2004). The project was part of the Hartford Geriatric Social Work Faculty Scholars Program Award, which is funded by the Gerontological Society of America and the John A. Hartford Foundation. The study was approved by the Fordham University Institutional Review Board (IRB) and met the standards for conducting research with a special population of older prisoners and on sensitive topics.

\subsection{Data collection}

The Dillman et al. (2009) method for mailed surveys was used to maximize response rates. Specifically, potential participants received: (1) a letter of invitation; (2) a packet with a cover letter, consent form, survey, and a self-addressed electronically stamped envelope (SASE) seven days later; (3) two thank you cards and reminders sent seven days apart that included an enclosed self-addressed envelope to request a survey replacement.

\subsection{Constructs and study measures}

Sexual victimization was measured using the 5 item subscale of the 31-item Life Stressors Checklist (LSC-R) (McHugo et al., 2005). The LSC-R sexual abuse subscale estimates the frequency of lifetime sexual abuse which is consistent with DSM IV-TR Criterion A for post trauma stress symptoms (APA, 2000). The LSC-R has good psychometric properties, including for use with diverse age groups and criminal justice populations. Researchers have reported that the LSC-R has demonstrated good criterion-related validity for detecting traumatic events, such as sexual abuse, among prisoners (McHugo et al., 2005). For example, McHugo et a1. (2005) collected data on 2,729 women in which a test-retest sample was completed on a subset of 186 women who completed the measure on average 7 days later. Kappa's range averaged .70 for different items.

\subsubsection{Objective occurrences of sexual victimization}

The LSC-R enables the measurement of 'objective' sexual abuse, which is defined in this study as whether or not one or more types of sexual abuse have occurred. Sexual abuse experiences are defined as those objective events that are consistent with DSM IV-TR Criterion A for PTSD (APA, 2000). Participants endorsed across 5 items as to whether or not each of these events occurred $(0=$ no; $1=$ yes). These items included sexual touch before and after the age of 16 , sexual harassment, and sexual assault before and after the age of 16 and were operationalized as follows.

1. Sexual touch before the age of 16 - "Before age 16 , were you ever touched or made to touch someone else in a sexual way because he/she forced you in some way or threatened to harm you if you didn't?"

2. Sexual assault before the age of 16 - "Before age 16, did you ever have sex (oral, anal, genital) when you didn't want to because someone forced you in some way or threatened to hurt you if you didn't?" 
3. Sexual harassment - "Have your ever been bothered or harassed by sexual remarks, jokes, or demands for sexual favors by someone at work or school (for example, a coworker, a boss, a customer, another student, a teacher)?"

4. Sexual touch after the age of 16 - "After age 16, were you ever touched or made to touch someone else in a sexual way because he/she forced you in some way or threatened to harm you if you didn't?"

5. Sexual assault after the age of 16 - "After age 16, did you ever have sex (oral, anal, genital) when you didn't want to because someone forced you in some way or threatened to harm you if you didn't?"

\subsubsection{Age of occurrence and subjective experiences of sexual victimization}

If participants endorsed 'yes' to an objective occurrence of traumatic or stressful life experiences, three follow-up items asked participants about their age and related post traumatic stress symptoms. As for age, it was measured as a continuous variable and participants were asked, "How old were you when this happened?" As for post traumatic stress symptoms, participants were asked: (1) "at the time of the event did you believe that you or someone else could be killed or seriously harmed?" (2) At the time of the event did you experience feelings of intense helplessness, fear, or horror?" Participants could respond yes or no to these two questions and they were measured as dichotomous/nominal level variables.

The LSC-R also includes a subscale for participants' 'subjective' impressions of sexual abuse victimization. For each of the types of sexual victimization experienced, participants were asked their current subjective impression of these events by asking them to rate each type of traumatic and stressful life event on the degree to which it was bothersome within this past year. Each item was measured using a five point Likert scale from $1=$ not at all to $5=$ extremely.

\subsubsection{Sexual offense history}

Sexual offense history was measured using the following self-report survey item: "Have you ever been charged with a sexual offense?" Participants could respond 'yes' or 'no'.

\subsection{Data analysis}

Descriptive statistics were used to examine the sociodemographic characteristics of sexual assault. A series of chi square analyses also were conducted to explore whether earlier life sexual abuse victimization (e.g., sexual touch before age 16, sexual assault before age 16, sexual touch after age 16, sexual assault after age 16, and sexual harassment) was related to the older adults' self-report sexual offense histories. All variables were dichotomous consisting of yes or no response categories.

\section{Major findings}

\subsection{Sample description}

The sample consisted of 667 adults (607 males and 24 females) serving prison sentences in a state correctional system in the north east United States in September 2010. The mean age of participants was 56.47 (sd =6.31). The participants' racial ethnic backgrounds consisted of African-American (45\%), White (36\%), Hispanic/Latino (10\%), and Other (9\%). Only $10 \%$ 
reported having no high school diploma and 30\% reported serving in the military. As for family, about $24 \%$ of participants reported currently being married or partnered. Furthermore, most participants reported having children (80\%), and over half reported having grandchildren $(62 \%)$.

About one third of participants reported having a mental health diagnosis $(36 \%)$ or a drug or alcohol problem (36\%). The majority had serious offenses, including sex offenses $(26 \%)$ and violent offenses (64\%). On average participants served 132 months (or 11 years). Over half of the participants were expected to be released from prison within one year $(37 \%)$ or 2 to 5 years (26\%); while approximately $10 \%$ were expected to be released within 6 to 10 years and $17 \%$ after eleven or more years.

\subsection{Sexual victimization: Objective and subjective experiences}

Table 1 presents the findings on the sexual victimization experience of the study sample. Both inappropriate sexual touch and assault were found to be twice as common before the age of 16 compared to after the age of 16 . More specifically, descriptive analyses revealed that $21.9 \%$ of the participants reported being a victim of inappropriate sexual touch before the age of 16 compared to $9.4 \%$ of the participants reported experiencing inappropriate sexual touch after the age of 16 . Similarly, $18.5 \%$ reported forced sexual assault before the age of 16 , while $9.1 \%$ reported sexual assault after the age of 16 . The lifetime occurrence of sexual harassment was reported by approximately 1 out of 10 participants. That is, $12.9 \%$ of participants endorsed having experienced sexual harassment in their lifetime.

As for age of sexual victimization, the data revealed that childhood sexual abuse began at an average age of 10 with a standard deviation of 4.4 for sexual touch and 3.6 for sexual assault. The average age reported for sexual harassment was $18.6(\mathrm{sd}=12.4)$. With regard to the subjective experiences of sexual touch or assault before or after age 16, most participants reported experiencing 'horror felt at the time' (ranging from 79.2\%-89.1\%). Furthermore, prior sexual touch and sexual assault appeared to have a lingering psychological effect. Many participants also reported that in the past year they felt 'moderately to extremely bothered by the incident in the past year' (ranging from $61.8 \%-75.4 \%$ ). In comparison to sexual touch and victimization, slightly less participants who experienced sexual harassment reported that they perceived that someone could have gotten hurt at the time $(36.5 \%)$, felt horror at the time $(62.7 \%)$, and were moderately to extremely bothered by it in the past year (55.1\%).

\begin{tabular}{|c|c|c|c|c|c|c|c|c|c|c|}
\hline \multirow[b]{2}{*}{ Traumatic Events } & \multicolumn{2}{|c|}{$\begin{array}{l}\text { Objective } \\
\text { Occurrences }\end{array}$} & \multicolumn{2}{|c|}{$\begin{array}{l}\text { Average Age } \\
\text { First Occurred }\end{array}$} & \multicolumn{2}{|c|}{$\begin{array}{l}\text { Believe Someone } \\
\text { Could Get Hurt }\end{array}$} & \multicolumn{2}{|c|}{$\begin{array}{l}\text { Horror Felt at } \\
\text { Time }\end{array}$} & \multicolumn{2}{|c|}{$\begin{array}{l}\text { Moderately to } \\
\text { Extremely } \\
\text { Bothered in Past } \\
\text { Year }\end{array}$} \\
\hline & $\%$ & $\mathrm{~N}$ & $\mathrm{M}$ & SD & $\%$ & $\mathrm{~N}$ & $\%$ & $\mathrm{~N}$ & $\%$ & $\mathrm{~N}$ \\
\hline 1. Sexual Touch < age 16 & 21.9 & 132 & 10.1 & 4.4 & 56.9 & 74 & 85.5 & 106 & 65.2 & 86 \\
\hline 2. Sexual Assault $<$ age 16 & 18.5 & 117 & 9.9 & 3.6 & 62.1 & 72 & 86.7 & 98 & 69.0 & 80 \\
\hline 3. Sexual Harassment & 12.9 & 78 & 18.6 & 12.4 & 36.5 & 27 & 62.7 & 47 & 55.1 & 43 \\
\hline 4. Sexual Touch $>$ age 16 & 9.4 & 57 & 16.6 & 9.5 & 64.9 & 37 & 89.1 & 49 & 75.4 & 43 \\
\hline 5. Sexual Assault $>$ age 16 & 9.1 & 55 & 19.6 & 11.1 & 62.7 & 32 & 79.2 & 42 & 61.8 & 34 \\
\hline
\end{tabular}

Table 1. Descriptive statistics for the Occurrence of Trauma and Mean Scores for Age First Occurred, Believe Someone would get hurt, Felt Horror at the Time, Moderately to

Extremely Bothered by it Past Year 


\subsection{Chi square results}

The results from the series of chi square tests that were run indicate that there is a significant relationship between having a sexual offense history and each of the sexual victimization variables (sexual touch before age $16\left(X^{2}=26.32, d f=1, p=.001\right)$, sexual assault before age 16 $\left(X^{2}=8.16, d f=1, p=.001\right)$, sexual touch after age $16\left(X^{2}=6.0, d f=1, p=.02\right)$, sexual assault after age $16\left(X^{2}=7.9, d f=1, p=.01\right)$, and sexual harassment $\left(X^{2}=10.5, d f=1, p=.001\right)$. These findings suggest that there is a relationship between prior sexual victimization and sexual offending.

\section{Conclusion}

\subsection{Overview of purpose and major findings}

The purpose of this chapter was to explore patterns of sexual abuse over the life-course among incarcerated older adult offenders and the relationship to sexual offense histories, and their temporal subjective experiences of trauma. This study corroborates prior results that find high prevalence rates of trauma among juvenile and adult prisoners (Abram et al., 2007). However, this study makes a number of significant contributions to the field. Firstly, it focuses in on traumatic experiences specific to sexual victimization. Secondly, it not only examines the objective occurrence of such experiences, but also examines incarcerated older adults' past year subjective impressions of these events, indicating significant present distress from past sexual abuse experiences. Thirdly, it examined and found support for a positive and significant relationship between having committed a sexual offense and experiences of sexual victimization.

\subsection{Implications}

Currently, the sexual abuse victimization experiences of older adults who also are incarcerated offenders have been largely ignored. This is a serious oversight since prison systems are known for being highly stressful environments in which older adults are at greater risk for the onset or resurfacing of post traumatic stress symptoms (Maschi, Gibson, Zgoba, \& Morgen, 2011). In court or prison intake assessment and pre-parole evaluations, subjective experiences, especially psychological distress related to past events, and sexual victimization, are not assessed. Without proper assessment, can older adults in prison access the types of services to help process unresolved sexual abuse experiences and take responsibility for their offenses?

In addition to adjustment to prison, about half of the incarcerated older adults are expected to be released to the community. There is potential for new federal proposals to aid in improving both advancing the discourse about these issues and improving practices for older adults in prison facilities. For example, in America, the Substance Abuse and Mental Health Services Administration (SAMHSA, 2011) recently created eight new initiatives (2011-2014), including trauma and justice. Programs that provide sexual abuse and sex offender specific treatment are warranted. Treatment options should be available from the point of entry into the correctional system, in preparation for re-entry into the community, and care after release.

As the findings suggest, significant differences were found between objective and subjective experiences of sexual abuse in this population. Understanding these differences and the more significant role that subjective experience plays for these participants, are essential in understanding, developing, and refining, effective screening instruments and implementing 
appropriate, trauma-informed interventions. This study supports the notion that assessing for objective and subjective distress related to these events also may be essential.

Along the same lines, evidence-based assessment and interventions must be in line with the finding of how significant the subjective impressions of sexual assault are for incarcerated older adults in treatment. A promising intervention that is being piloted in the criminal justice system with younger age groups is Eye Movement Desensitization and Reprocessing (EMDR). EMDR specifically targets change in subjective units of distress among trauma survivors, particularly sexual abuse survivors, which in turn reduces post traumatic stress symptoms (Kitchiner, 2000). Moreover, previous research with incarcerated juvenile offenders shows that EMDR can work in reducing post traumatic stress reactivity resulting in less violent behavior and conduct problems among samples. Its utility for older adults, especially those with histories of sexual assault victimization and perpetration is perhaps a promising intervention. The use of evidence-based practices suggests that untreated trauma and grief are related to increased adult recidivism rates (Leach et al., 2008). Therefore, treating psychological distress and untreated symptoms effectively, which involves both screening and treatment that captures subjective experiences, may help to break the cycle of recidivism and in some case sexual offending.

\subsection{Limitations and future research directions}

This study has notable limitations. First, the study used a cross-sectional design thus precluding causal inferences about the relationship between sexual victimization and sexual offending. The study sample from a northeast state prison system may not be representative of and generalizable to prisoners in other geographic locations and non-English speaking participants. Using a mailed self-administered survey may be another limitation because of possible low response rates and possible limited literacy levels.

Perhaps most importantly, while the data found in this study related to sexual abuse are slightly higher than in the general public, it is imperative to consider that these numbers are still not representative of the actual rates of sexual victimization in older prisoners. Offenders often do not endorse a history of sexual abuse even if it is present. For instance, research shows that $40 \%$ of randomly selected male inmates met the criteria for being a victim of sexual abuse. However, $41 \%$ of those people did not consider themselves to have been sexually abused (Fondacaro, Holt \& Powell, 1999). Similarly, results from a large study by the Alaska Department of Corrections (1998) of prisoners in Alaska reveal that while $70 \%$ of respondents endorsed a history of sexual acts prior to the age of 12 , all of which would indicate sexual abuse, only $12 \%$ of them considered the experiences to be sexual abuse (Langworthy, Barnes, \& Curtis, 1998). As a result, it must be considered a possibility that these numbers are lower than actuality.

The findings of this study support the need for future research to examine the relationship between sexual offending and sexual victimization among incarcerated older offenders. This includes studies that examine a broad range of sexual victimization and how these experiences influence subjective physical and mental well-being and criminal offending, including sexual offending. A longitudinal study examining reactivity among ex-offenders after reentry would greatly benefit the field and provide evidence for policy makers to implement such trauma-informed treatments within the prison system and community correctional programs. 


\subsection{Conclusion}

In conclusion, this study attempted to fill a gap in the literature about earlier sexual abuse victimization experiences among incarcerated older adults and the relationship to sexual offending histories. Overall, the plight of older adults in the criminal justice system has largely been ignored. Continuing to neglect the later life aftermath of earlier life sexual abuse experiences may have detrimental effects on the individual experiencing them then and now.

\section{Acknowledgment}

The project was part of the Hartford Geriatric Social Work Faculty Scholars Program Award, which is funded by the Gerontological Society of America and the John A. Hartford Foundation.

\section{References}

Abram, K. M., Washburn, J. J., Teplin, L. A., Emanuel, K. M., Romero, E. G., \& McClelland, G. M. (2007). Posttraumatic stress disorder and psychiatric comorbidity among detained youths. Psychiatric Services, 58(10), 1311-1316.

Acierno, R, Hernandez, M.A., Amstadter, A.B., Resnick, H.S, Steve, K; Muzzy, W; \& Kilpatrick, D. (2010). Financial abuse and potential neglect in the united states: The national elder mistreatment study. American Journal of Public Health, 100(2),292-297.

Acierno, R, Lawyer, S.R, Rheingold, A, Kilpatrick, D.G, Resnick, H.S; \& Saunders, B.E. (2007). Current psychopathology in previously assaulted older adults. Journal of Interpersonal Violence, 22(2), 250-258.

Aday, R. H. (2003). Aging prisoners: Crisis in American corrections. Westport, CT: Praeger.

Aday, R. H. (2006). Aging offenders' concerns toward dying in prison. OMEGA: Journal of Death and Dying, 52(3), 199-216.

American Psychiatric Association. (2000). Diagnostic and statistical manual of mental disorders (TR). Washington, DC: Author.

Brown, Governor of California, et al. v. Plata et al., 2011.

Cauffman, E., Feldman, S., Waterman, J \& Stiener, H. (1998). Posttraumatic stress disorder among female juvenile offenders. Journal of the American Academy of Child and Adolescent Psychiatry 37: 1209-216.

Cox, J. F. \& Lawrence, J.E. (August 2010). Planning services for elderly inmates with mental illness. (Library ID. 024489.) National Institute of Corrections.

Dawes, J. (2009). Ageing Prisoners: Issues for social work. Australian Social Work, 62(2), 258271.

Draper, B., Pfaff, J., Pirkis, J., Snowdon, J., Lautenschlager, N., Wilson, I., et al. (2008). Longterm effects of childhood abuse on the quality of life and health of older people: Results from the depression and early prevention of suicide in general practice project. Journal of the American Geriatrics Society, 56(2), 262-271.

Falter, R.G. (2006). Elderly inmates: An emerging correctional population. Correctional Health Journal, 1, 52-69.

Fondacaro, K., Holt, J. \& Powell, T. (1999). Psychological impact of childhood sexual abuse on male inmates: The importance of perception. Child Abuse and Neglect, 23, $361-369$.

Ford, J. D., Hartman, K., Hawke, J., \& Chapman, J. F. (2008). Traumatic victimization, posttraumatic stress disorder, suicidal ideation, and substance abuse risk among juvenile justice-involved youth. Journal of Child and Adolescent Trauma, 1, 75-92. 
Gagnon, M., \& Hersen, M. (2000). Unresolved childhood sexual abuse and older adults: Late-life vulnerabilities. Journal of Clinical Geropsychology, 6(3), 187-198.

Glaze, L.E. (2009). Correctional population in the US, 2009. (NCJ Publication No. 231681). Washington, DC: US Department of Justice.

Goff, A., Rose, E., Rose, S., \& Purves, D. (2007). Does PTSD occur in sentenced prison populations? A systematic literature review. Criminal Behavior $\mathcal{E}$ Mental Health, 17(3), 152-162.

Harlow, C. W. (1999). Prior abuse reported by inmates and probationers. (NCJ Publication No. 172879). Rockville, MD: U.S. Department of Justice.

Haugebrook, S., Zgoba, K., Maschi, T., Morgen, K., \& Brown, D. (2010). Trauma, stress, health, and mental health issues among ethnically diverse older adult prisoners. Journal of Correctional Health Care, 16(3), 220-229.

Hiskey, S., Luckie, M., Davies, S., \& Brewin, C. (2008). The phenomenology of reactivated trauma memories in older adults: A preliminary study. Aging $\mathcal{E}$ Mental Health, 12(4), 494-498.

Hochstetler, A., Murphy, D. S., \& Simons, R. L. (2004). Damaged goods: Exploring predictors of distress in prison inmates. Crime $\mathcal{E}$ Delinquency, 50(3), 436-457.

James, D. J., \& Glaze, L. E. (2006). Mental health problems of prison and jail inmates. (NCJ Publication No. 213600). Rockville, MD: U.S. Department of Justice.

Kitchiner, N. J. (2000, February). Using EMDR to treat post-traumatic stress disorder in a prison setting. British Journal of Community Nursing, 5(1), 26-31.

Krause, N. (2004). Lifetime trauma, emotional support, and life satisfaction among older adults. The Gerontologist, 44(5), 615-623.

Lamet, A., Szuchman, L., Perkel, L., \& Walsh, S. (2009). Risk factors, resilience, and psychological distress among holocaust and nonholocaust surviviors in the post9/11 environment. Educational Gerontology, 35(1), 32-46.

Langworthy, H., Barnes, R, \& Curtis, R. (1998). Results From the Long-Term Inmate Survey: Focus on Child Abuse Histories. Report prepared for the Alaska Department of Corrections. Anchorage, AK: Justice Center, University of Alaska Anchorage.

Leach, R.M., Burgess, T., \& Holmwood, C. (2008) Could recidivism in prisoners be linked to traumatic grief? A review of the evidence. International Journal of Prisoner Health, 4(2), 104-119.

Maruschak, L. M. (2008). Medical problems of offenders. (NCJ Publication No. 221740). Rockville, MD: U.S. Department of Justice.

Maschi, T. (2006). Exploring the link between trauma and delinquency: The cumulative versus differential risks. Social Work, 1, 59-75.

Maschi, T., Dennis, K., Gibson, S., MacMillan, T., Sternberg, S., \& Hom, M. (2011). Trauma and stress among older adults in the criminal justice system: A review of the literature with implications for social work. Journal of Gerontological Social Work, 54, 347-360.

Maschi, T., Gibson, S., Zgoba, K.M., \& Morgen, K. (2011). Trauma and life event stressors among young and older offenders, Journal of Correctional Healthcare, 17(2), 160-172.

Maschi, T., Morgen, K., Zgoba, K., Courtney, D., \& Ristow, J. (2011). Trauma, stressful life events, and post traumatic stress symptoms: Do subjective experiences matter? The Gerontologist. doi:10.1093/geront/gnr074

McDaniels Wilson, C. \& Belknap, J. (2008). The extensive sexual violation and sexual abuse histories of incarcerated women. Violence Against Women, 14, 1090-1127. 
Neal, L., Hill, N., Hughes, J., Middleton, A., \& Busuttil, W. (1995). Convergent validity of measures of PTSD in an elderly population of former prisoners of war. International Journal of Geriatric Psychiatry, 10(7), 617-622.

Reimer, G. (2008). The graying of the U.S. offender population. Journal of Correctional Health Care, 14, 202-208.

Sabol, W.J. \& West, H.C. (2009). Prisoners in 2008. (NCJ Publication No. 228417). Washington, DC: U.S. Department of Justice.

Sabol, W. J., \& Couture, H. (2008). Prison inmates at midyear 2007. (NCJ Publication No. 221944). Rockville, MD: U.S. Department of Justice.

Shmotkin, D., \& Barilan, Y. (2002). Expressions of Holocaust experience and their relationship to mental symptoms and physical morbidity among holocaust survivor patients. Journal of Behavioral Medicine, 25(2), 115-134.

Shmotkin, D., \& Litwin, H. (2009). Cumulative adversity and depressive symptoms among older adults in Israel: the differential roles of self-oriented versus other-oriented events of potential trauma. Social Psychiatry \& Psychiatric Epidemiology, 44, 989-997. doi:10.1007/s00127-009-0020-x

Shimkus, J. (2004). The graying of America's prisons: Corrections copes with care for the aged. Retrieved July 2007 from http://www.ncchc.org/pubs/CC/aging_inmates.html

Stesssman, J., Cohen, A., Hammerman-Rozenberg, R., Bursztyn, M., Azoulay, D., Maaravi, Y., et al. (2008). Holocaust survivors in old age: The Jerusalem Longitudinal Study. Journal of the American Geriatrics Society, 56(3), 470-477.

Stojkovic, S. (2007). Elderly offenders: A growing and forgotten group within correctional systems vulnerable to elder abuse. Journal of Elder Abuse E Neglect, 19(3/4), 97-117.

Stop Prisoner Rape. (2003). The sexual abuse of female inmates in Ohio. Retrieved from http://www.justdetention.org/pdf/sexabuseohio.pdf

Struckman-Johnson, C., Struckman-Johnson, D., Rucker, L., Bumby, K., \& Donaldson, S. (1996). Sexual coercion reported by men and women in prison. Journal of Sex Research, 33(1), 67-76.

Substance Abuse and Mental Health Services Administration [SAMHSA] (2011). Leading change: A plan for SAMHSA's roles and actions. Retrieved May 7, 2011 from http://store.samhsa.gov/shin/content//SMA11-4629/04-TraumaAndJustice.pdf

Teplin, L.A. (1990). "The prevalence of severe mental disorder among male urban jail detainees: Comparison with the epidemiologic catchment area program." American Journal of Public Health, 80, 663-669.

van der Kolk, B. A., \& Fisler, R.E. (1994). Child abuse and neglect and loss of self-regulation. Bulletin of the Menninger Clinic, 58, 10-23.

van der Kolk, B.A. (Ed.). (1987). Psychological trauma. Washington, DC: American Psychiatric Association.

van der Kolk, B.A., McFarlane, A.C., \& Weisaeth, L. (Eds.). (1996). Traumatic stress: The effects of overwhelming experience on mind, body, and society. New York: Guildford Press.

West, H. C., \& Sabol, W. J. (2008). Prisoners in 2007. (NCJ 224280). Rockville, MD: U.S. Department of Justice.

Widom, C. (1989). Does violence beget violence? A critical examination of the literature. Psychological Bulletin, 106, 3-28

Yehuda, R., Kahana, B., Schmeidler, J., Southwick, S., Wilson, S., \& Giller, E. (1995). Impact of cumulative lifetime trauma and recent stress on current postraumatic stress disorder symptoms in Holocaust survivors. American Journal of Psychiatry, 152(12), 1815-1818. 


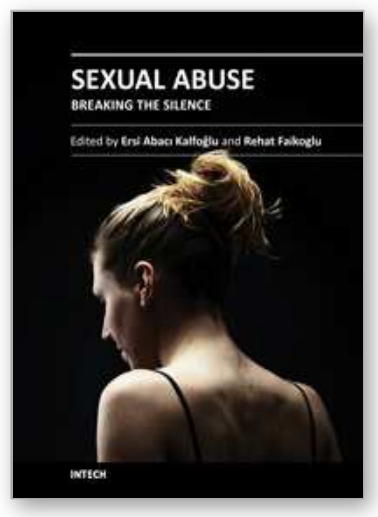

\author{
Sexual Abuse - Breaking the Silence \\ Edited by Dr. Ersi Abaci Kalfoğlu
}

ISBN 978-953-51-0425-4

Hard cover, 238 pages

Publisher InTech

Published online 23, March, 2012

Published in print edition March, 2012

Sexual assault can be considered as expression of aggression through sex. This, in turn, can have serious negative effects on a survivor's social and occupational functioning. This book has been organized towards that specific approach, by compiling the scientific work of very well-known scientists from all over the world. The psychological victimization of sexual assault, the physiological aspect of sexual abuse and the different attitudes in coping with sexual assault based on different cultural backgrounds are analyzed. Having in mind that one solution may not necessarily be suitable for all cases, we hope that this book will open a debate on sexual assault for future practice and policy and that it will be a step forward to 'break the silence'.

\title{
How to reference
}

In order to correctly reference this scholarly work, feel free to copy and paste the following:

Mary Beth Morrissey, Deborah Courtney and Tina Maschi (2012). Sexual Abuse Histories Among Incarcerated Older Adult Offenders: A Descriptive Study, Sexual Abuse - Breaking the Silence, Dr. Ersi Abaci Kalfoğlu (Ed.), ISBN: 978-953-51-0425-4, InTech, Available from: http://www.intechopen.com/books/sexual-abuse-breakingthe-silence/sexual-abuse-histories-among-incarcerated-older-adults-a-descriptive-study

\section{INTECH}

open science | open minds

\section{InTech Europe}

University Campus STeP Ri

Slavka Krautzeka 83/A

51000 Rijeka, Croatia

Phone: +385 (51) 770447

Fax: +385 (51) 686166

www.intechopen.com

\section{InTech China}

Unit 405, Office Block, Hotel Equatorial Shanghai

No.65, Yan An Road (West), Shanghai, 200040, China 中国上海市延安西路65号上海国际贵都大饭店办公楼 405 单元

Phone: +86-21-62489820

Fax: +86-21-62489821 
(C) 2012 The Author(s). Licensee IntechOpen. This is an open access article distributed under the terms of the Creative Commons Attribution 3.0 License, which permits unrestricted use, distribution, and reproduction in any medium, provided the original work is properly cited. 